\title{
触 New Disease Reports \\ First report of loose kernel smut of sorghum caused by Sporisorium cruentum in Egypt
}

M.H.A. Moharam

Plant Pathology Department, Faculty of Agriculture, Sohag University, P.O. 82755, El-Kawamel, Sohag, Egypt

*E-mail: moustafa.moharam@agr.sohag.edu.eg

Received: 09 Jan 2018. Published: 27 Feb 2018. Keywords: basidiomycota, fungal plant disease, panicle, ustilaginales

In 2017, sorghum plants (Sorghum bicolor cv. Dorado) cultivated in several areas in Upper Egypt (Qena governorate), exhibited symptoms of loose kernel smut disease (Fig. 1). In the field, plants affected by loose kernel smut were initially mostly stunted, had thin stems, and panicles which emerged earlier than those of healthy plants. Later, all kernels of infected panicles were replaced by smut sori (approx. 1.0-1.5 $\mathrm{cm} \times 0.4-0.5 \mathrm{~cm}$ ). The sori were surrounded by a thin grey membrane that often ruptured soon after the panicle emerged from the stem. Following rupture of the membrane, a powdery and black smut mass (teliospores) was dispersed leaving a clearly visible central and curved columella inside the sorus.

Panicles of infected plants were collected in paper bags. Smut masses were passed through a sieve (100 micron filter) and stored at ambient temperature in the laboratory for further study. The smut fungus was identified as Sporisorium cruentum based on morphological characteristics of the teliospores and their germination on water agar (Tarr, 1962; Langdon \& Fullerton, 1978; Frederiksen \& Odvody, 2000). Teliospores were spherical, tinted, smooth and 6-10 um in diameter. They germinated on water agar forming a four-celled promycelium (basidium) on which terminal and lateral sporidia (spindle-shaped or oblong) were produced.

Koch's postulates were performed in pots under greenhouse conditions to confirm the pathogenicity of five selected isolates. Grain of sorghum cv. Dorado was surface sterilised with $70 \%$ ethanol for two minutes, soaked in sterile tap water for six hours, air-dried and inoculated by thoroughly dusting them with teliospores at the rate $5 \mathrm{~g} / \mathrm{kg}$ of grain (Moharam et al. 2012). After inoculation, five grains were sown in each pot and the pots were irrigated daily. The growing plants were left until panicles emerged and symptoms appeared. Symptoms were similar to those observed in panicles of sorghum plants infected in the field. Identical teliospore morphology and germination of fungus was observed from infected panicles of artificially inoculated plants. Mycelium of $S$. cruentum was also observed in tissues of the apical buds and nodes of inoculated plants (28 days after germination) when hand-cut sections were stained with trypan blue (Fig. 2) using the technique described by Moharam et al. (2012)
Control plants inoculated with sterile sorghum flour remained healthy. This experiment was repeated twice producing identical results.

The causal organism is less widespread than $S$. sorghi and S. ehrenbergii which cause covered kernel and long smut, respectively in West Africa and Asia, moreover it attacks all sorghum species causing considerable yield reduction (Gwary et al., 2009; Kutama et al., 2011). In Egypt, this is the first report of loose kernel smut on sorghum.

\section{Acknowledgements}

The author would like to thank Mr. Ahmed Amer in the Agricultural Research Station, ARC, El Matana, Qena for his kind help and technical assistance.

\section{References}

Gwary DM, Bdliya BS, Bwatanglang N, 2009. Integration of fungicides, crop varieties and sowing dates for the management of sorghum smuts in Nigerian Savanna. Archives of Phytopathology and Plant Protection 42, 988-999. http://dx.doi.org/10.1080/03235400701543988

Frederiksen RA, Odvody GN, 2000. Compendium of Sorghum Diseases. St. Pauls, USA: APS Press.

Kutama AS, Aliyu BS, Emechebe AM, 2011. Screening of sorghum genotypes for resistance to loose smut in Nigeria. Bayero Journal of Pure and Applied Sciences 4, 199-203.

Langdon RFN, Fullerton RA, 1978. The genus Sphacelotheca

(Ustilaginales): criteria for its delimination and the consequences thereof. Mycotaxon 6, 421-456.

Moharam MHA, Leclerque A, Koch E, 2012. Cultural characteristics of Sporisorium sorghi and detection of the pathogen in plant tissue by microscopy and polymerase chain reaction. Phytoparasitica 40, 475-483. http://dx.doi.org/10.1007/s12600-012-0248-y

Tarr SAJ, 1962. Diseases of Sorghum, Sudan Grass and Broom Corn. Kew, UK: Commonwealth Mycological Institute.

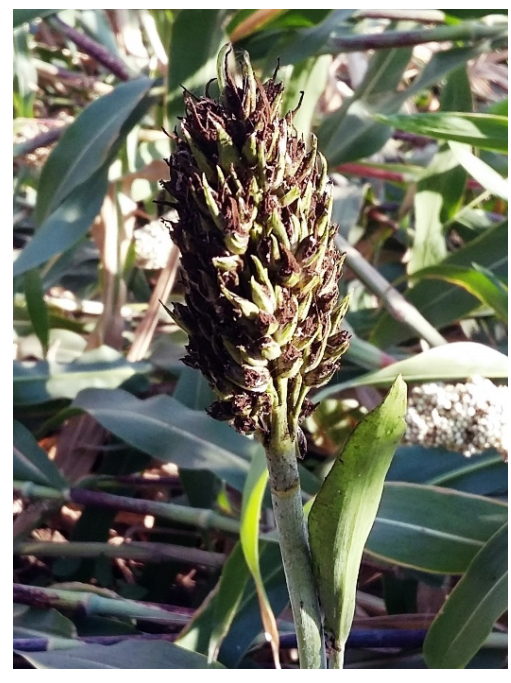

Figure 1

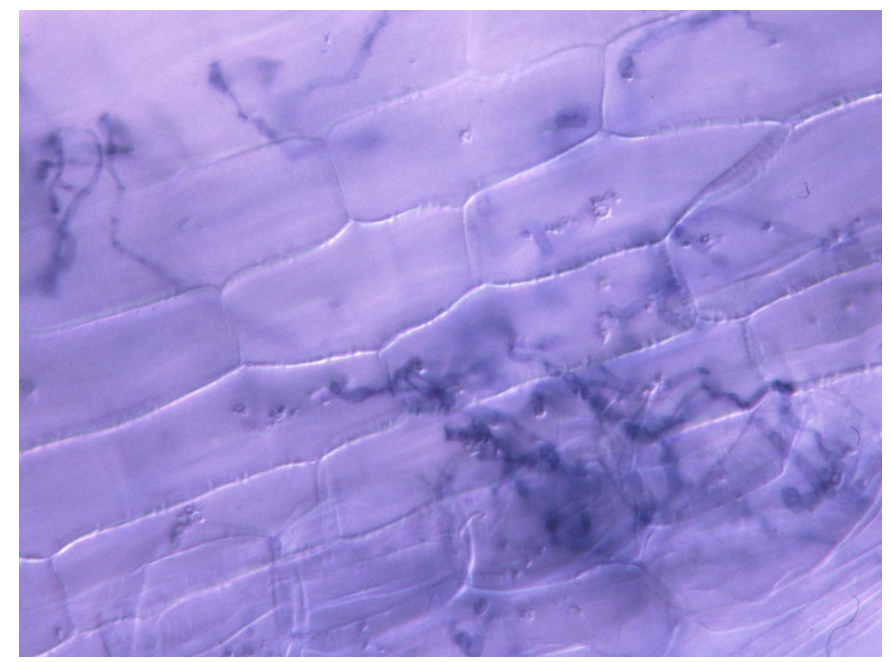

Figure 2

To cite this report: Moharam MHA, 2018. First report of loose kernel smut of sorghum caused by Sporisorium cruentum in Egypt. New Disease Reports 37, 9. http://dx.doi.org/10.5197/j.2044-0588.2018.037.009

(C) 2018 The Authors

This report was published on-line at www.ndrs.org.uk where high quality versions of the figures can be found. 